\title{
Life-Cycle Analyses of Energy Consumption and GHG Emissions of Natural Gas-Based Alternative Vehicle Fuels in China
}

\author{
Xunmin $\mathrm{Ou}^{1,2}$ and Xiliang Zhang ${ }^{1,2}$ \\ ${ }^{1}$ Institute of Energy, Environment and Economy (3E), Tsinghua University, Beijing 100084, China
}

${ }^{2}$ China Automotive Energy Research Center, Tsinghua University, Beijing 100084, China

Correspondence should be addressed to Xunmin Ou; ouxm@mail.tsinghua.edu.cn

Received 26 February 2013; Accepted 24 April 2013

Academic Editor: Qilian Liang

Copyright (C) 2013 X. Ou and X. Zhang. This is an open access article distributed under the Creative Commons Attribution License, which permits unrestricted use, distribution, and reproduction in any medium, provided the original work is properly cited.

Tsinghua life-cycle analysis model (TLCAM) has been used to examine the primary fossil energy consumption and greenhouse gas (GHG) emissions for natural gas- (NG-) based alternative vehicle fuels in China. The results show that (1) compress NGand liquid NG-powered vehicles have similar well-to-wheels (WTW) fossil energy uses to conventional gasoline- and dieselfueled vehicles, but differences emerge with the distance of NG transportation. Additionally, thanks to NG having a lower carbon content than petroleum, CNG- and LNG-powered vehicles emit 10-20\% and 5-10\% less GHGs than gasoline- and diesel-fueled vehicles, respectively; (2) gas-to-liquid- (GTL-) powered vehicles involve approximately $50 \%$ more WTW fossil energy uses than conventional gasoline- and diesel-fueled vehicles, primarily because of the low efficiency of GTL production. Nevertheless, since NG has a lower carbon content than petroleum, GTL-powered vehicles emit approximately $30 \%$ more GHGs than conventionalfuel vehicles; (3) The carbon emission intensity of the LNG energy chain is highly sensitive to the efficiency of NG liquefaction and the form of energy used in that process.

\section{Background}

\subsection{Alternative Vehicle Fuels in China}

1.1.1. General Background. During the period of the eleventh five-year (2006-2010) plan, the Chinese automobile market experienced strong growth. Vehicle ownership increased 20\% annually during that period, amounting to 87 million by the end of 2010. This strong growth promoted a steadily increasing demand for fuels and, accordingly, a substantial escalation in petroleum prices. Meanwhile, pollutant and carbon dioxide $\left(\mathrm{CO}_{2}\right)$ emissions associated with petroleum combustion also posed major environmental concerns. Consequently, alternative vehicle fuels are gaining increasing interest.

Currently, several nonconventional fuels have been marketed as alternatives to regular vehicle fuels (i.e., gasoline and diesel); these include vehicular natural gas-compressed natural gas (CNG) and liquefied natural gas (LNG) biodiesel, methanol-gasoline blends, ethanol-gasoline blends, and coal-derived fuels. Electric vehicles have also been introduced as a potential solution to the disadvantages of vehicles consuming conventional fuels.

The study of CAERC (2012) [1] found that the ownership of natural gas vehicles in China exceeded 500,000 as of 2010; annually 4.6 million tons of vehicular gasoline and diesel are being replaced by natural gas in 2010 .

Moreover, the annual consumption of methanol-gasoline blends, biofuels, and coal-derived fuels was 200 million tons, 1.83 million tons, and 33,000 tons, respectively. The annual saving of gasoline and diesel by electric vehicles is less than 40,000 tons. In total, these alternative fuels replace only a fraction $(3.3 \%)$ of China's vehicular gasoline and diesel consumption. However, the acceptance of alternative vehicle fuels is profoundly affected by industrial productivity and governmental policies. Furthermore, their acceptance may have a substantial impact on local liquid fuel markets. 
1.1.2. Current Status. Two types of natural gas products have received attention as alternative vehicle fuels-CNG and LNG.

CNG Vehicle Fuel. According to the NGV Global (2012) [4] statistic, as of June of 2010, the ownership of natural gas vehicles in China exceeded 1,104,000; $98.9 \%$ of them are CNGV. Currently, CNG vehicles are in use in 30 provinces (cities or autonomous regions) of China. As of 2010, the officially registered $\mathrm{CNG}$ vehicle ownership amounted to 20,000. Taking unregistered vehicles into account (i.e., CNG vehicles converted from regular-fuel autos), the total number of CNG vehicles exceeded 500,000. Meanwhile, CNG station development has made considerable progress. As of 2009, there were 1,055 CNG stations across China, which was 500 more than there were at the end of 2007.

Statistical data of China LNG Vehicle Net (CLNGVN, 2012) [5] in 2010 from several regions where CNG vehicles have been relatively popular (i.e., Sichuan, Chongqing, Harbin, Urumqi, and Xian) show that CNG vehicles are primarily used as city buses (replacing diesel buses), taxicabs (replacing gasoline taxis), and governmental automobiles. Approximately $80 \%$ of these vehicles were used for commercial purposes.

According to the NGV Global (2012) [4], as of June of 2012, the ownership of natural gas vehicles in China exceeded 1.1 million; $98.9 \%$ of them are CNGV.

Current high gasoline prices reinforce the economic advantages of CNG vehicles. As a result, these vehicles have been well marketed in regions with abundant natural gas sources. However, owing to technical limitations (e.g., fuel availability and difficulties in fuel station construction), CNG vehicles are primarily suitable for city buses and shortdistance transport. As of 2010, there were 600,000 CNG vehicles in China, which consumed 6 billion cubic meters of CNG annually as a replacement for 2.76 million tons of gasoline and 260,000 tons of diesel.

LNG Vehicle Fuel. LNG vehicles have not been widely utilized in China, primarily owing to the lack of LNG sources, the high cost of conversion to LNG, and lack of LNG fueling stations. According to a survey of seven Chinese cities in 2010, 2,800 LNG vehicles were in operation, of which $56 \%$ were city buses; a significant proportion of the remainder were accounted for by heavy trucks. For example, 400 LNG heavy trucks were used by the Guanghui Industry Investment Group (Xinjiang, China) for LNG delivery, and point-topoint transport between coal plants. In 2010, several cities (e.g., Erdos, Zhuhai) undertook pilot programs to promote the replacement of heavy diesel trucks by LNG alternatives.

Thus far, LNG vehicles are primarily being operated at the demonstration stage. Although LNG terminals began operation in Jiangsu and Dalian in 2011, they mainly targeted specific industrial users.

In recent 2 years, LNG vehicle market has developed very quickly and the ownership of LNG vehicles in China exceeded 70 thousand million; the numbers of LNG refueling stations reached to about 500 as the end of October of 2012 (CLNGVN, 2012) [5].
Consequently, LNG has played a more and more important role as an alternative to diesel as a fuel for vehicles.

\subsubsection{Impact of Alternative Vehicle Fuels on Gasoline Demand} in China. In 2010, the above-mentioned alternative fuels served as a replacement for approximately 3.3\% (i.e., 7.1 million tons) of the total annual consumption of regular vehicle fuels. Specifically, gasoline alternatives (CNG, methanol, ethanol, and electricity) reduced annual vehicular gasoline consumption by approximately 6.6\% (i.e., 60,000 tons). Diesel alternatives (LNG, coal-derived fuel, and biodiesel) were used to replace approximately $1.8 \%$ of annual vehicular diesel consumption. Of the various alternative vehicle fuels, CNG appears to be the most successful, accounting for $83 \%$ of gasoline substitution and $71 \%$ of that for diesel.

1.2. Life-Cycle Studies on Vehicle Fuels. Life-cycle analyses (LCAs) of energy consumption and greenhouse gas (GHG) emissions are an important component in assessing vehicle fuel pathways. Many studies have produced results that pertain to specific geographic locations (Zhang et al., 2008) [2].

In the last two decades, there have been intensive studies of alternative fuels and related vehicle technologies. Models have been used to analyze fuel use and carbon emissions of various alternative-fuel routes, such as the life-cycle emission model (LEM) and the greenhouse gas, regulated emissions, and energy use of transportation energy (GREET) model [6-9]. Many organizations and research groups have used the two models in their LCAs of alternative-fuel vehicles in various regions, such as Europe and North America [10, 11]. Their findings are highly region specific, and thus cannot be directly applied to other locations. By employing different models, researchers have investigated the LCA results of different energy pathways, including the natural gas pathway globally [12-21].

In China, earlier LCA studies focused on single-route analyses of passenger cars, new-energy vehicles, and vehicle operation (e.g., engine bench tests). Recent studies have increasingly focused on two- and multiple-route comparisons. However, these recent studies have lacked statistical information or basic data reflecting actual vehicle operations; many conclusions were drawn from experiments or predictions. Consequently, it is difficult to make a direct comparison between the findings from different studies.

Recently, Tsinghua University collaborated with Ford, General Motor, and the China Automotive Technology and Research Center (CATARC) to perform comparative LCAs for multifuel and vehicle pathways of vehicles using the GREET model. Because the original GREET model and default parameters were designed based on the energy production chain in the United States, the Chinese research team maximally incorporated localized data into its analyses. Thus, the results generally reflect the actual operation conditions in China $[2,3,22]$. 


\section{Tsinghua Life-Cycle Analysis Model and Key Emission Intensities}

The present study investigated the energy use and GHG emissions of various vehicle fuel pathways using the wellto-wheels (WTW) method and related LCA tools. This study focused only on LCA and included no subsequent evaluations.

The group has developed an LCA model termed the Tsinghua life-cycle analysis model (TLCAM), which is specifically designed to analyze vehicle fuels in China. The model is analogous to the GREET model (Wang, 1999) - a transportation energy model specific to the United States-and is implemented using Microsoft Excel (Microsoft, Redmond, WA, USA). TLCAM has been applied to WTW analyses of vehicle fuels under localized conditions in China [23-28].

The basic platform in this model was adapted from the GREET model, though it incorporates Chinese characteristics. The platform allows the user to determine the life-cycle fossil fuel intensities and GHG emission intensities of major end-use energies by means of iterative calculations.

In the present study, three primary fossil fuels were considered: coal, petroleum, and natural gas (NG). Nine forms of end-use energy were analyzed, including coal, petroleum, NG-based fuels, and electricity. The life cycle was divided into four phases for analysis: raw material production, raw material transport, fuel production, and fuel transport.

In our analyses, the system boundary was extended to cover the direct use of fuels (i.e., for processing and transport purposes), LCA energy consumption, and GHG emissions. However, indirect energy consumption (e.g., plant infrastructure construction and vehicle manufacture) was ignored.

This model clearly involves circular references. For example, petroleum mining and transportation require diesel, which is itself produced from petroleum. We solved this problem by using the circular reference function (i.e., iterative calculation) offered in Microsoft Excel. Finally, the platform outputs datasheets that detail the LCAs of the energy and carbon-emission intensities of various end-use energies.

In the current study, this model was used to generate the life-cycle primary fossil fuel intensities and major end-use energies in addition to their carbon emission intensities. The resulting datasheets were used as the basis (see Section 3) for subsequent analysis.

\section{Basic Data}

\subsection{Energy Data}

3.1.1. Petroleum and Refined Products. Table 1 summarizes data related to petroleum mining, transportation, and refining. Table 2 presents details of the transportation and distribution of refined petroleum products. It should be noted that petroleum-refining processes require the use of dry gas, which is not, however, one of the nine end-use energies considered in this study. This situation thus required special consideration: in the present study, dry gas was regarded as a
TABLE 1: Energy-efficiency data related to petroleum mining and refining $(\%){ }^{\dagger}$

\begin{tabular}{lc}
\hline Item & Value \\
\hline Proportion of crude oil import & 55.4 \\
Extraction efficiency of crude oil & 93.0 \\
Energy efficiency of gasoline production & 89.1 \\
Energy efficiency of diesel production & 89.7 \\
Energy efficiency of fuel oil production & 94.0 \\
\hline
\end{tabular}

${ }^{\dagger}$ Data assembled from publications [2,3] and expert opinions.

raw material that involves the consumption of no additional primary fossil fuels, and it has a GHG intensity of $65 \mathrm{~g} / \mathrm{MJ}$.

3.1.2. Natural Gas. Tables 3 and 4 summarize the data related to the extraction, processing, transport, and distribution of natural gas.

3.2. Carbon Emission-Related Estimations. For our model, the carbon content and oxidation ratios of various types of energy were collected from an authoritative work containing basic data on GHG emissions in China. Methane $\left(\mathrm{CH}_{4}\right)$ emission factors for the combustion of oil and gas fuels under different facility conditions were obtained from IPCC report [29] and a report published by the 3E-THU (2003) [30]. The report was supported by the Ministry of Science and Technology of China and completed in collaboration with experts in the petroleum and petrochemical industries. The report estimated the methane emissions associated with various processes involved in the extraction, processing, transport, and consumption of petroleum and natural gas in China. Additionally, methane emission factors for coal combustion under different facility conditions were also collected. Nitrous oxide $\left(\mathrm{N}_{2} \mathrm{O}\right)$ emission factors under various conditions used in the model were the default values published by IPCC (2006) [29].

It should be noted that natural gas extraction operations involve a small fraction (approximately $0.34 \%$ ) of methane loss into the atmosphere.

\section{WTW Classification of Phases of NG Fuels}

After extraction and purification, NG is delivered to plants, where it is processed into liquid fuels or CNG for vehicle use. Figure 1 summarizes the life-cycle phases of NG fuels.

This section is primarily concerned with the energy use and GHG emissions of fuels. Specifically, our analyses were focused on two phases: well to pump (WTP) and pump to wheels (PTW). WTP refers to the upstream processes in vehicle fuel production, including resource extraction, resource transport, and the production, transport, distribution, storage, and tank-filling of fuel products. PTW refers to the downstream processes, including primarily the use (combustion) of fuels by vehicles and exhaust emissions.

In our analyses, the system boundary covered the direct use (i.e., process and traffic purposes) of fuels, as well as the LCA energy consumption and GHG emissions. Indirect 
TABLE 2: Data related to petroleum transport and the transport and distribution of refined petroleum products. ${ }^{\dagger, \ddagger}$

\begin{tabular}{|c|c|c|c|c|}
\hline \multirow{2}{*}{ Transport mode } & \multicolumn{2}{|c|}{ Crude oil } & \multicolumn{2}{|c|}{ Gasoline, diesel, and fuel oil } \\
\hline & Percentage (\%) & $\begin{array}{c}\text { Average transport } \\
\text { distance }(\mathrm{km})\end{array}$ & Percentage (\%) & $\begin{array}{c}\text { Average transport } \\
\text { distance }(\mathrm{km})\end{array}$ \\
\hline Ocean shipping & 50 & 11000 & 0 & 0 \\
\hline Train & 30 & 942 & 50 & 900 \\
\hline Pipeline & 78 & 440 & 15 & 160 \\
\hline Ship & 10 & 250 & 10 & 1200 \\
\hline $\begin{array}{l}\text { Short-distance vehicle } \\
\text { transport }\end{array}$ & 0 & 0 & 10 & 50 \\
\hline
\end{tabular}

${ }^{\dagger}$ Data assembled from publications [2,3] and expert opinions.

${ }^{\ddagger}$ Owing to relay during transport, the sum of data for all modes may exceed $100 \%$.
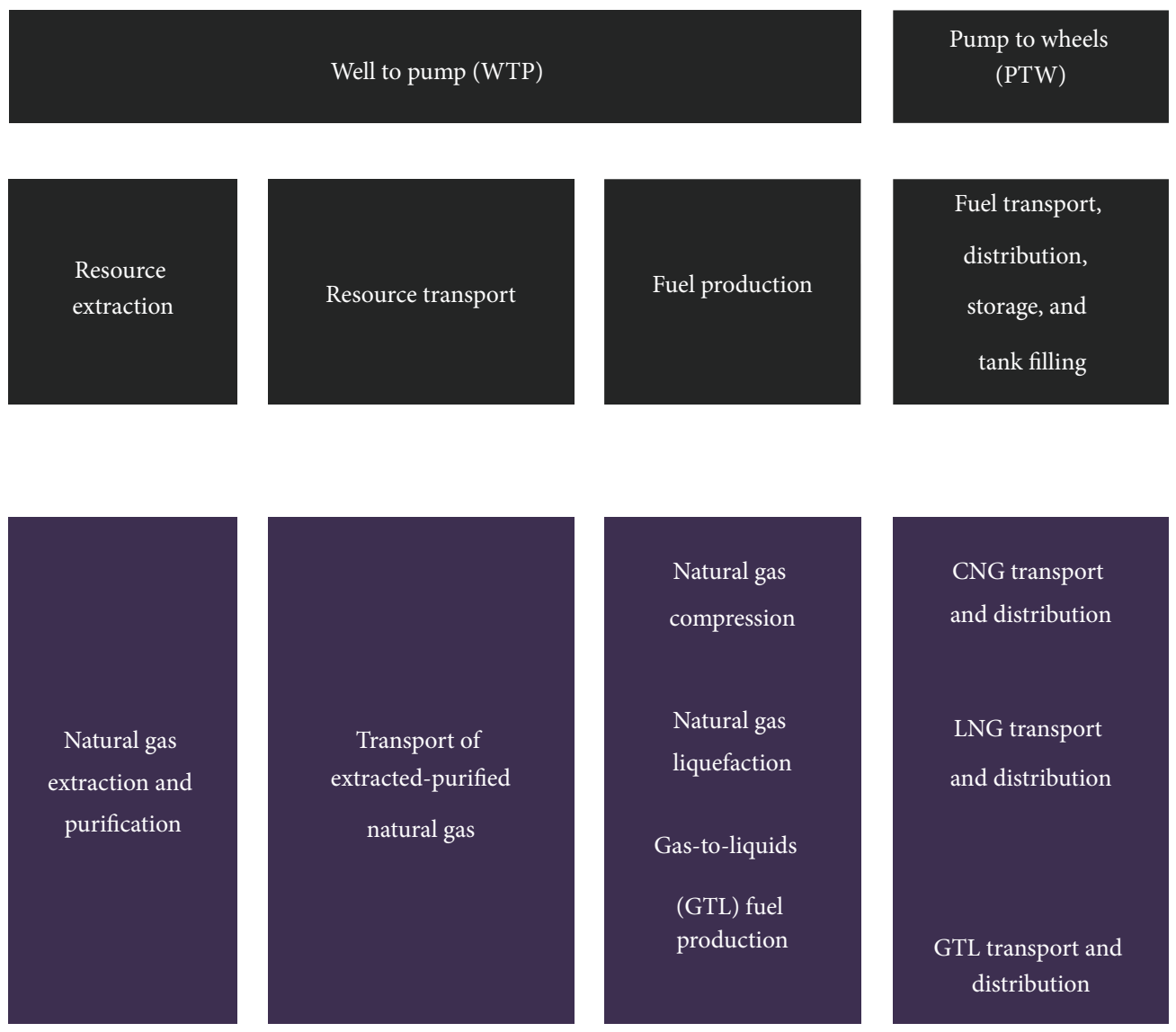

FIGURE 1: WTW classification of phases of NG fuels.

TABLE 3: Energy-efficiency data related to natural gas extraction and processing (\%).

\begin{tabular}{ll}
\hline Item & Value \\
\hline Extraction efficiency of natural gas & 96.00 \\
Natural gas processing efficiency & 94.00 \\
\hline
\end{tabular}

energy consumption (e.g., plant infrastructure construction and vehicle production) was ignored. However, our analyses considered methane loss (i.e., leakage to the atmosphere) during the production of coal, raw natural gas, and crude oil.
TABLE 4: Data related to pipeline transport of natural gas.

\begin{tabular}{lc}
\hline Application & Average transport distance $(\mathrm{km})$ \\
\hline Compressed natural gas & 625 \\
Process fuel & 1500 \\
\hline
\end{tabular}

\section{Energy Consumption and Carbon Emissions during Various Phases}

5.1. NG Extraction and Processing. In a previous study, CATARC (2007) [3] analyzed four major NG fields of 
PetroChina (the fields account for $70 \%$ of all natural gas productivity in China) and predicted that the energy efficiency for NG extraction would be approximately $96.4 \%$ in 2015 . Given the limited variation in this energy efficiency, we set it at $96 \%$ in our analyses. Additionally, Shen et al. (2012) [22] reported that the energy consumption for NG extraction and processing (i.e., purification) in China was approximately $10 \%$. Accordingly, the energy efficiency of natural processing (i.e., purification) was estimated to be $94 \%$; that is, $(100 \%-$ $10 \%) / 96 \%=94 \%$. Meanwhile, NG extraction and processing primarily consume NG and electricity; the latter is usually provided by gas-fired power stations operated by the same NG fields and processing plants.

NG contains mainly methane, a major GHG. Consequently, methane leakage during NG extraction and processing contributes substantially to GHG emissions. The level of this leakage affects the energy efficiency and emissionreduction performance of $\mathrm{NG}$ fuels as alternative vehicle fuels.

5.2. CNG Production. CNG fueling stations mainly use electricity, water, and other resources. Additionally, they involve NG loss in the emptying of containers or pipelines. According to CATARC (2007) [3], the energy efficiency for NG compression is $96.9 \%$, and this process involves the loss of $\mathrm{NG}\left(0.038 \mathrm{MJ} / \mathrm{m}^{3} \mathrm{NG}\right)$ and other energy sources $\left(0.56 \mathrm{MJ} / \mathrm{m}^{3}\right.$ NG).

5.3. LNG Production. LNG-related processes primarily include liquefaction plants and LNG reception stations. The energy consumption involved in these processes includes electricity, water, and other resources. For imported LNG, the related energy consumption and efficiency were obtained from the GREET model. The comprehensive energy consumption was determined to be $90.2 \%$, which included predominantly NG (98\%) and a small fraction of electricity (2\%). For LNG produced in China, there were two technical possibilities: (1) liquefaction near the gas field followed by short-distance transport and distribution for vehicle use; (2) long-distance pipeline transport of NG followed by liquefaction and short-distance transport and distribution for vehicle use. After consultation with the China National Offshore Oil Corp., we set the comprehensive energy efficiency for LNG production in China at 95\%. LNG production consumes primarily electricity.

5.4. Gas-to-Liquid (GTL) Fuel Production. Currently, there is no GTL fuel production in China, and data related to the energy use of this process were obtained from the GREET model. The comprehensive energy consumption for this process was set at $54.2 \%$. This process consumes predominantly NG $(99.7 \%)$ and a minor fraction $(0.3 \%)$ of $n$-butane.

5.5. NG Transport and Product Fuel Transport and Distribution. After purification, NG is generally transported by a long-distance pipeline to reach industrial users or city hubs. After delivery to city hubs, NG is further transported and distributed to final users. In recent years, the average distance of NG pipeline transport in China has rapidly increasedfrom $217 \mathrm{~km}$ in 1998 and $496 \mathrm{~km}$ in 2004 to $800 \mathrm{~km}$ in 2005. Moreover, several long-distance pipelines have been constructed, such as the west-east natural gas transmission engineering $(3,900 \mathrm{~km})$ and the China-Kazakhstan pipeline $(3,000 \mathrm{~km})$. In light of this trend, the average distance of NG pipeline transport was set at $1,500 \mathrm{~km}$.

Because WTW analysis of NG-based vehicle fuels is sensitive to the mode and distance of NG transport, different transport distances were set for CNG, LNG, and GTL. The transport distance for $\mathrm{CNG}$ production is usually the average distance for NG transport within the country. Since CNG vehicles are predominantly used currently in regions with rich NG resources, the typical pipeline transport distance is approximately $300 \mathrm{~km}$ (e.g., the distance between the Kaixian gas field and Chongqing), and subsequent delivery is accomplished by vehicle transport.

Similar to earlier analyses (Section 5.3), three routes of NG supply application were considered: overseas import; local liquefaction followed by vehicle transport; pipeline transport followed by liquefaction and subsequent transport and distribution for vehicle use. For the first route, the average transport distance was set at 6,700 km (Shen et al., 2012) [22]. For the second route, the average vehicle transport distance was assumed to be $100 \mathrm{~km}$. For the third route, the distance for transport and distribution was also set at $100 \mathrm{~km}$.

For GTL fuels, an appropriate means of supply and application consists of production near gas fields followed by transport and distribution to final users. In this study, the typical distance between the gas field and the production plant was assumed to be $100 \mathrm{~km}$, and the subsequent transport and distribution were assumed to be similar to those for diesel.

Moreover, the following assumption was made for estimating the energy consumption for NG transport: pipeline transport is driven by gas turbines that consume mainly NG (90\%) and external electricity (10\%) from the power grid. Data related to the energy consumption for overseas shipment of LNG were obtained from the GREET model.

5.6. Carbon Emissions during Various Phases of NG-Based Fuel Production and Use. In this section, carbon-emission patterns associated with the production and use of various phases of NG-based fuels (i.e., NG, CNG, LNG, and GTL) are analyzed.

5.6.1. Natural Gas. According to our calculations, the upstream processes account for $14.1 \%$ of the life-cycle GHG emissions of NG production and use: this comprises $12.6 \%$ emitted during NG extraction and processing and $1.5 \%$ by subsequent transport. Combining the GHG emissions during upstream processes and final applications, the NG energy chain produces total carbon emissions of $67.1 \mathrm{~g} \mathrm{CO}_{2, \mathrm{e}} / \mathrm{MJ}$.

5.6.2. CNG. For CNG, the upstream processes account for $21.2 \%$ of the life-cycle GHG emissions. Of these, NG extraction, NG transport, NG compression, and CNG transport amount to $11.6 \%, 0.3 \%, 9.3 \%$, and $0.0 \%$, respectively, of the total GHG emissions. In combination with GHG emissions 
from upstream processes and final application, this energy chain totally emits $73.2 \mathrm{~g} \mathrm{CO}_{2, \mathrm{e}} / \mathrm{MJ}$.

5.6.3. LNG Fuel. As described earlier, three supply routes were considered (Section 5.5). Our calculations suggest that for the first route (overseas import followed by supply to local cities for vehicle use), the upstream processes amount to $24.0 \%$ of the life-cycle GHG emissions: this comprises $11.2 \%$ from natural extraction, 9.4\% from NG compression, $2.6 \%$ from LNG transport, and $0.8 \%$ from LNG distribution. Under this route, the LNG energy chain totally emits $75.7 \mathrm{~g} \mathrm{CO}_{2, \mathrm{e}} / \mathrm{MJ}$.

For the second route (liquefaction near gas fields followed by truck transport for vehicle use), the upstream processes account for $25.7 \%$ of the life-cycle GHG emissions: this comprises $10.9 \%$ from NG extraction, $14.0 \%$ from liquefaction, and $0.8 \%$ from LNG transport and distribution. Combining upstream processes and final application, the energy chain under this route totally emits $77.5 \mathrm{~g} \mathrm{CO}_{2, \mathrm{e}} / \mathrm{MJ}$.

For the third route (NG pipeline transport followed by liquefaction and further transport and distribution for vehicle use), the upstream processes account for $26.7 \%$ of the life-cycle GHG emissions: this comprises $10.8 \%$ from NG extraction and processing, $1.3 \%$ from NG transport and distribution, $13.8 \%$ from liquefaction, and $0.8 \%$ from LNG transport and distribution. Combining upstream processes and final application, the energy chain under this route totally emits $78.5 \mathrm{~g} \mathrm{CO}_{2, \mathrm{e}} / \mathrm{MJ}$.

5.6.4. GTL Fuel. For the application of GTL as an alternative vehicle fuel, the upstream processes amount to $48.0 \%$ of the life-cycle GHG emissions: this comprises $7.7 \%$ from NG extraction, $0.1 \%$ from NG transport, $40.1 \%$ from GTL production, and $0.2 \%$ from GTL transport and distribution. Combining upstream processes and final use, the GTL energy chain totally emits $146.8 \mathrm{~g} \mathrm{CO}_{2, \mathrm{e}} / \mathrm{MJ}$.

\section{Life-Cycle GHG Emission: Analysis and Summary}

Using a medium-size passenger car with an energy efficiency of 8 liters of gasoline consumed per $100 \mathrm{~km}$ as the baseline model, we can calculate the WTW fossil energy input and GHG emissions of such pathways as those for gas-based fuels. For different vehicle and fuel technology pathways, the fuel economy situation is presented in ratios using gasoline spark ignition (SI) vehicles as the baseline: diesel is $110 \%, \mathrm{CNG}$ is 95.0\%, LNG is $99.1 \%$, and GTL is $110 \%$. It should be noted that the vehicles are gauged under hypothetical conditions with heating and air-conditioning in use. The fuel consumption in real operating conditions is about $15 \%$ higher than in laboratory tests for inner combustion engine (ICE) vehicles.

Figures 2 and 3 summarize the GHG emission behavior of various NG-based fuels for vehicles. CNG- and LNGpowered vehicles have similar WTW fossil energy uses to conventional gasoline- and diesel-fueled vehicles, but differences emerge with the distance of NG transportation. Additionally, thanks to NG having a lower carbon content
WTW fossil energy use $(\mathrm{Mj} / \mathrm{km})$

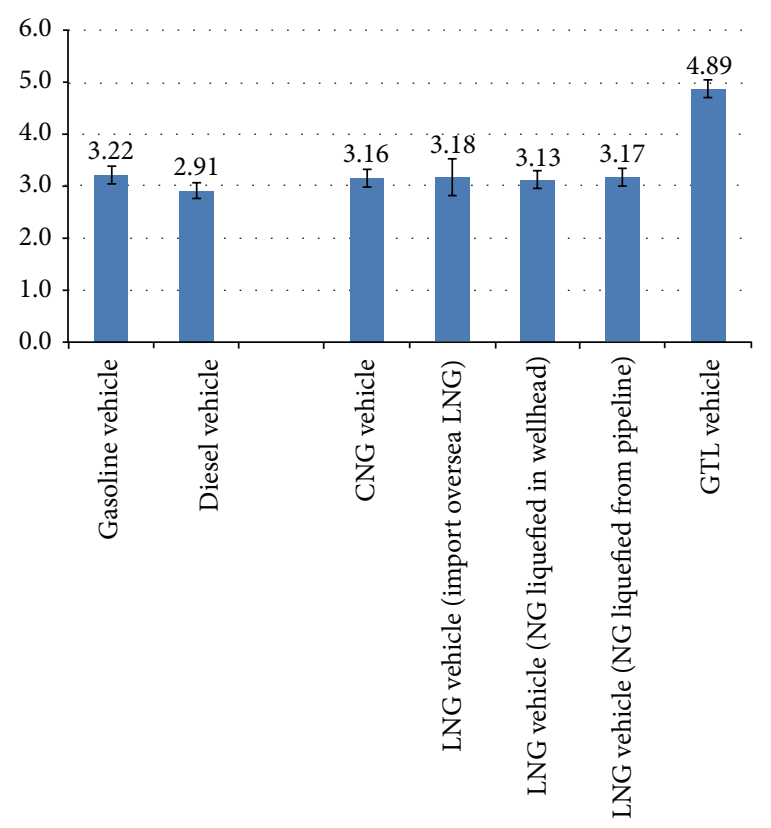

FIGURE 2: WTW fossil energy use of vehicles powered by NG-based fuels $(\mathrm{MJ} / \mathrm{km})$.

than petroleum, CNG- and LNG-powered vehicles emit $10-20 \%$ and $5-10 \%$ less GHGs than gasoline- and dieselfueled vehicles, respectively. We assumed that errors in our modeling of CNG and LNG fuels would mainly arise with respect to the actual distance of transport.

However, GTL-powered vehicles involve approximately $50 \%$ more WTW fossil energy use than conventional gasoline- and diesel-fueled vehicles, primarily because of the low efficiency of GTL production. Nevertheless, since NG has a lower carbon content than petroleum, GTL-powered vehicles emit approximately $30 \%$ more GHGs than conventionalfuel vehicles. We considered uncertainty over the efficiency of future GTL production technology as representing a significant area of error in our analyses.

Since LNG is primarily targeted at commercial vehicles, we made efforts to compare the application of this alternative fuel for heavy trucks and buses. However, because of the lack of consistent data, it was difficult to make an accurate comparison. According to a study by Tang et al. (2011), the replacement ratio for diesel to NG is 90:100 (in terms of net energy). However, according to another source (http://wenku.baidu.com/view/75a1357e168884868762d6ba .html\#\#\#), the diesel-to-NG replacement ratio should be 78:100 (in net energy). Because of this inconsistency, we performed calculations using these two values as the upper and lower limits. We found that, depending on the replacement ratio, LNG-powered vehicles may emit either $5 \%$ less or $12 \%$ more GHGs than conventional-fuel vehicles.

\section{Sensitivity of Carbon Footprint of LNG}

This section analyzes the sensitivity of the carbon footprint of LNG as an alternative vehicle fuel. 
WTW GHG emission $\left(\mathrm{g} \mathrm{CO}_{2, \mathrm{e}} / \mathrm{km}\right)$

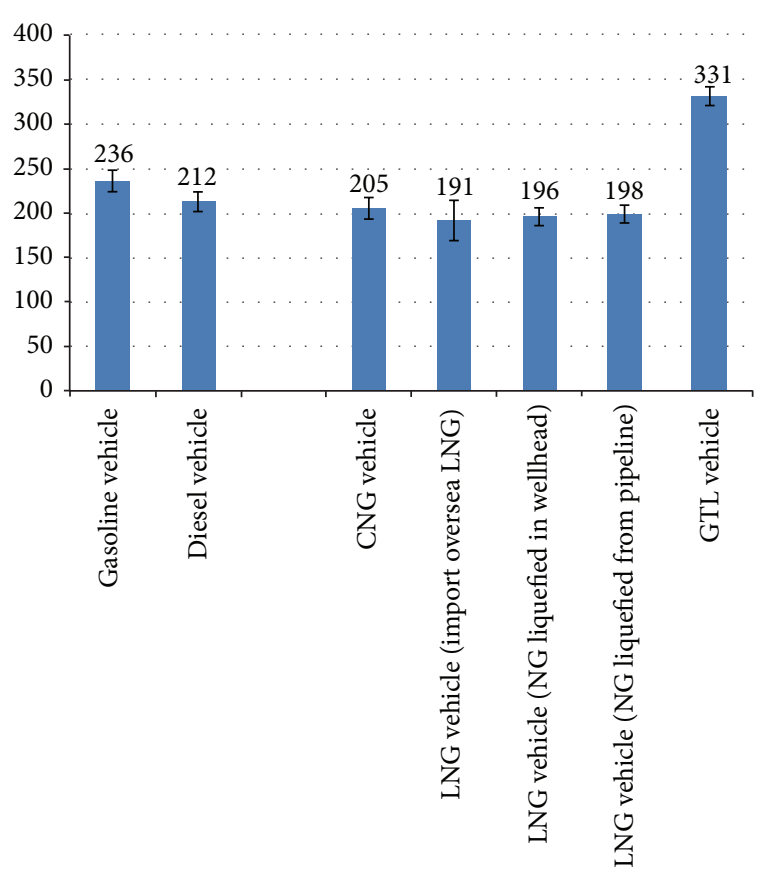

FIGURE 3: WTW GHG emission levels of vehicles powered by NGbased fuels $\left(\mathrm{g} \mathrm{CO}_{2, \mathrm{e}} / \mathrm{km}\right)$.

7.1. Effect of LNG Supply Routes. As mentioned earlier (Section 5.5), three LNG supply routes were considered in this study: (1) overseas import (average shipment distance, $6,700 \mathrm{~km}$ (Shen et al., 2012) followed by supply to local cities (average transport distance, $100 \mathrm{~km}$ ); (2) liquefaction near gas fields followed by truck transport (average distance, $100 \mathrm{~km}$ ) for final vehicle use; (3) NG pipeline transport followed by liquefaction, transport, and distribution (distance, $100 \mathrm{~km}$ ) for vehicle use. Our analyses suggest that the first route involves the lowest carbon intensity $\left(75.7 \mathrm{~g} \mathrm{CO}_{2, \mathrm{e}} / \mathrm{MJ}\right)$ and the second route the highest carbon intensity $\left(78.5 \mathrm{~g} \mathrm{CO}_{2, \mathrm{e}} / \mathrm{MJ}\right)$. The third route results in intermediate carbon intensity of $77.5 \mathrm{~g} \mathrm{CO}_{2, \mathrm{e}} / \mathrm{MJ}$.

7.2. Impact of Energy Efficiency and Energy Sources in NG Liquefaction. The carbon intensity of the LNG energy chain varied substantially with the type of energy used for NG liquefaction. Our calculations suggest that under the first supply route, assuming that the liquefaction plant uses electricity at a comprehensive energy efficiency of $95.2 \%$, the upstream processes contribute $27.5 \%$ of the life-cycle GHG emissions. Combining these upstream processes and the subsequent LNG application, the LNG energy chain totally emits $79.3 \mathrm{~g} \mathrm{CO}_{2, \mathrm{e}} / \mathrm{MJ}$. This value amounts to a $4.8 \%$ higher carbon intensity than with another assumed situation (liquefaction primarily using NG).

Under the second route, assuming that the plant uses primarily NG at a comprehensive energy efficiency of $90.2 \%$, the upstream processes contribute $21.6 \%$ of the life-cycle GHG emissions. Combining these upstream processes and final application, the LNG energy chain is expected to emit a total $73.5 \mathrm{~g} \mathrm{CO}_{2, \mathrm{e}} / \mathrm{MJ}$. This value amounts to a $5.2 \%$ lower carbon intensity than with another situation (liquefaction using electricity).

Moreover, with the third route, assuming that the liquefaction plant uses primarily NG at a comprehensive energy efficiency of $90.2 \%$, the upstream processes contribute $22.7 \%$ of the life-cycle GHG emissions. Considering the upstream processes and final application, this energy chain totally emits $74.4 \mathrm{~g} \mathrm{CO}_{2, \mathrm{e}} / \mathrm{MJ}$. This emission level results in a $5.2 \%$ lower carbon intensity than with another assumed operation situation (liquefaction using electricity).

7.3. Effects of $N G$ Transport. Under the three supply modes, reducing the transport distance for $\mathrm{NG}$ and LNG by $50 \%$ decreased the carbon intensity as follows: from $75.7 \mathrm{~g} \mathrm{CO}_{2, \mathrm{e}} / \mathrm{MJ}$ to $74.5 \mathrm{~g} \mathrm{CO}_{2, \mathrm{e}} / \mathrm{MJ}$ (first mode, $1.7 \%$ decrease); from $77.5 \mathrm{~g} \mathrm{CO}_{2, \mathrm{e}} / \mathrm{MJ}$ to $77.2 \mathrm{~g} \mathrm{CO}_{2, \mathrm{e}} / \mathrm{MJ}$ (second mode, $0.4 \%$ decrease); from $78.5 \mathrm{~g} \mathrm{CO}_{2, \mathrm{e}} / \mathrm{MJ}$ to $77.7 \mathrm{~g} \mathrm{CO}_{2, \mathrm{e}} / \mathrm{MJ}$ (third mode, $1.1 \%$ decrease).

7.4. Summary for the Sensitivity Analysis. Our calculations suggest that the carbon emission intensity of the LNG energy chain is highly sensitive to the efficiency of NG liquefaction and the form of energy used in that process. Moreover, this carbon emission intensity is moderately sensitive to different feedstock supply and fuel-production pathways but relatively insensitive to the distance of NG transport and LNG transport and distribution.

\section{Concluding Remarks}

(1) CNG- and LNG-powered vehicles have similar WTW fossil energy uses to conventional gasoline- and diesel-fueled vehicles, but differences emerge with the distance of NG transportation. Additionally, thanks to NG having a lower carbon content than petroleum, CNG- and LNG-powered vehicles emit $10-20 \%$ and $5-10 \%$ less GHGs than gasolineand diesel-fueled vehicles, respectively.

(2) However, GTL-powered vehicles involve approximately 50\% more WTW fossil energy uses than conventional gasoline- and diesel-fueled vehicles, primarily because of the low efficiency of GTL production. Nevertheless, since NG has a lower carbon content than petroleum, GTLpowered vehicles emit approximately $30 \%$ more GHGs than conventional-fuel vehicles.

(3) The carbon emission intensity of the LNG energy chain is highly sensitive to the efficiency of NG liquefaction and the form of energy used in that process.

\section{Acknowledgments}

The project is cosupported by the China National Natural Science Foundation (Grant no. 71041028, 71103109, and 71073095), China National Social Science Foundation (09 \& ZD029), MOE Project of Key Research Institute of Humanities and Social Sciences at universities in China (2009JJD790029), and the CAERC program (Tsinghua/GM/ SAIC-China). 


\section{References}

[1] CAERC (China Automotive Energy Research Center, Tsinghua University), China Automotive Energy Outlook 2012, Scientific Press, Beijing, China, 2012.

[2] A. L. Zhang, W. Shen, W. J. Han, and Q. H. Chai, Life Cycle Analysis of Automotive Alternative Fuel, Tsinghua University Press, Beijing, China, 2008.

[3] CATARC (China Automotive Technology and Research Center), Well-to-Wheels Analysis of Energy Consumption and GHG Emissions of Multi Vehicle Fuel in Future China, CATARC, Beijing, China, 2007.

[4] NGV Global (natural gas vehicle global), "China's NGV Growth Accelerating," 2012, http://www.iangv.org/category/ country/china/.

[5] CLNGVN (China LNG Vehicle Net), "LNG buses soar up in China," 2012, http://www.lngche.com/article-1396-1.html.

[6] M. A. Delluchi, Emissions of GHG from the Use of Transportation Fuels and Electricity-Volume1: Main Text, Center for Transportation Research, Argonne National Laboratory, Lemont, Ill, USA, 1991.

[7] M. A. Delluchi, A Lifecycle Emissions Model (LEM): Main Texts, Institute of Transportation Studies. University of California, Davis, Calif, USA, 2003.

[8] M. Wang, GREET 1. 5-Transportaion Fuel-Cycle Model-Volume 1: Methodology, Development, Uses, and Results, Center for Transportation Research, Argonne National Laboratory, Lemont, Ill, USA, 1999.

[9] M. Wang, H. Lee, and J. Molburg, "Allocation of energy use in petrol refineries to petrol products," International Journal of Life Cycle Assessment, vol. 9, no. 1, pp. 34-44, 2004.

[10] Concawe, EUCAR and EC Joint Research Centre, "Well-towheels analysis of future automotive fuels and powertrains in the European context," 2007, http://iet.jrc.ec.europa.eu/ about-jec/sites/iet.jrc.ec.europa.eu.about-jec/files/documents/ wtw3_wtw_report_eurformat.pdf.

[11] J. Wallace, M. Wang, T. Weber, and A. Finizza, "GM study: wellto-wheel energy use and greenhouse gas emissions of advanced fuel/vehicle systems-North American analysis," Tech. Rep., 2001, http://greet.es.anl.gov/publication-3plz9fyi.

[12] M. A. Weiss, J. B. Heywood, E. M. Drake, A. Schafer, and F. F. AuYeung, "On the road in 2020," Tech. Rep. MIT EL 00-003, Laboratory for Energy and the Environment (LFEE), Cambridge, Mass, USA, 2000.

[13] M. A. Weiss, J. B. Heywood, A. Schafer, and V. K. Natarajan, "Comparative assessment of fuel cell cars," Tech. Rep. MIT LFEE, 2003-001 RP, Laboratory for Energy and the Environment (LFEE), Cambridge, Mass, USA, 2003.

[14] J. Ally and T. Pryor, "Life-cycle assessment of diesel, natural gas and hydrogen fuel cell bus transportation systems," Journal of Power Sources, vol. 170, no. 2, pp. 401-411, 2007.

[15] D. Karman, "Life-cycle analysis of GHG emissions for CNG and diesel buses in Beijing," in Proceedings of IEEE EIC Climate Change Technology Conference (EICCCC '06), pp. 1-6, May 2006.

[16] L. Kliucininkas, J. Matulevicius, and D. Martuzevicius, “The life cycle assessment of alternative fuel chains for urban buses and trolleybuses," Journal of Environmental Management, vol. 99, pp. 98-103, 2012.

[17] F. Ryan and B. Caulfield, "Examining the benefits of using bioCNG in urban bus operations," Transportation Research D, vol. 15, no. 6, pp. 362-365, 2010.
[18] L. Rose, M. Hussain, S. Ahmed, K. Malek, R. Costanza, and E. Kjeang, "A comparative life cycle assessment of diesel and compressed natural gas powered refuse collection vehicles in a Canadian city," Energy Policy, vol. 52, pp. 453-461, 2013.

[19] A. Arteconi, C. Brandoni, D. Evangelista, and F. Polonara, "Lifecycle greenhouse gas analysis of LNG as a heavy vehicle fuel in Europe," Applied Energy, vol. 87, no. 6, pp. 2005-2013, 2010.

[20] CARB (California Air Resource Board), "Comparison of greenhouse gas emissions from natural gas and diesel vehicles," Tech. Rep. 08/10/2008.CARB, 2008.

[21] O. P. R. van Vliet, A. P. C. Faaij, and W. C. Turkenburg, "FischerTropsch diesel production in a well-to-wheel perspective: a carbon, energy flow and cost analysis," Energy Conversion and Management, vol. 50, no. 4, pp. 855-876, 2009.

[22] W. Shen, W. J. Han, D. Chock, Q. H. Chai, and A. L. Zhang, "Well-to-wheels life-cycle analysis of alternative fuels and vehicle technologies in China," Energy Policy, vol. 49, pp. 296-307, 2012.

[23] X. Li, X. Ou, X. Zhang, Q. Zhang, and X. L. Zhang, "Lifecycle fossil energy consumption and greenhouse gas emission intensity of dominant secondary energy pathways of China in 2010," Energy, vol. 50, pp. 15-23, 2013.

[24] X. Ou, Y. Xiaoyu, and X. Zhang, "Life-cycle energy consumption and greenhouse gas emissions for electricity generation and supply in China," Applied Energy, vol. 88, no. 1, pp. 289-297, 2011.

[25] X. Ou, X. Zhang, S. Chang, and Q. Guo, "Energy consumption and GHG emissions of six biofuel pathways by LCA in China," Applied Energy, vol. 86, no. 1, pp. S197-S208, 2009.

[26] X. Ou, X. Zhang, and S. Chang, "Alternative fuel buses currently in use in China: life-cycle fossil energy use, GHG emissions and policy recommendations," Energy Policy, vol. 38, no. 1, pp. 406418, 2010.

[27] X. Ou, X. Zhang, and S. Chang, "Scenario analysis on alternative fuel/vehicle for China's future road transport: life-cycle energy demand and GHG emissions," Energy Policy, vol. 38, no. 8, pp. 3943-3956, 2010.

[28] X. M. Ou and X. L. Zhang, Life-Cycle Analysis of the Automotive Energy Pathways in China, Tsinghua University Press, Beijing, China, 2011.

[29] IPCC (Intergovernmental Panel on Climate Change), "IPCC Guidelines for National GHG Inventories," 2006.

[30] 3E-THU (Institute of Energy, Environment and Economy at Tsinghua University), Report of Inventory of CH4 Emission Sources and Sinks of China's Petroleum and Natural Gas Sector in 2000, Institute of Energy, Environment and Economy, Tsinghua University, Beijing, China, 2003. 


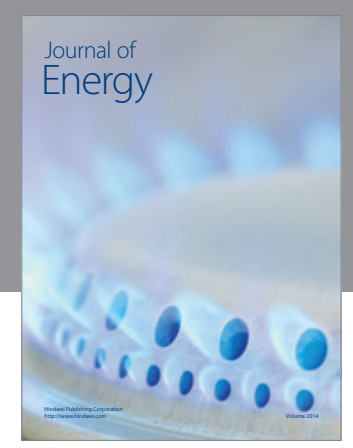

Journal of

Industrial Engineering
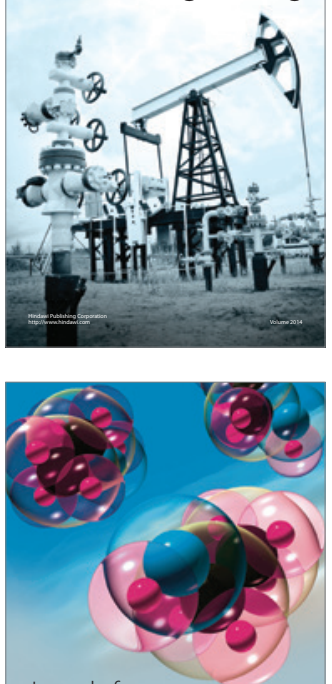

Fuels
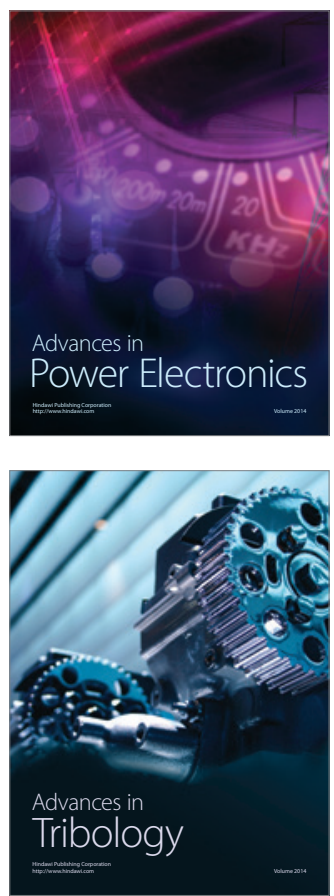

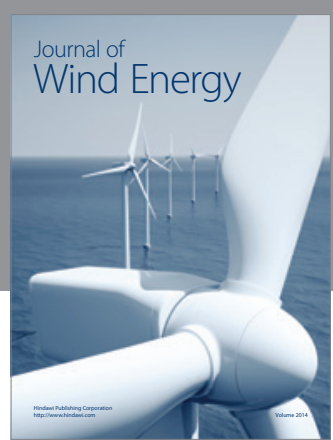

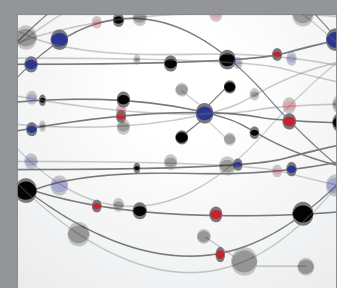

The Scientific World Journal

Submit your manuscripts at http://www.hindawi.com

Journal of

Structures
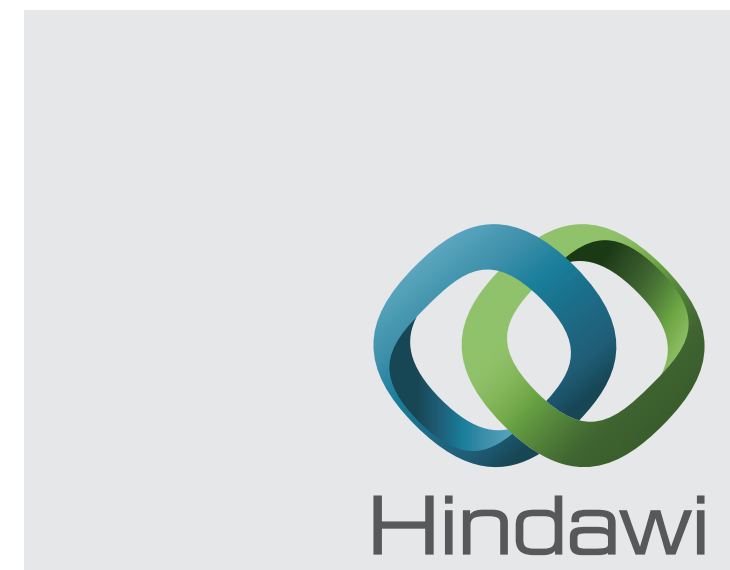

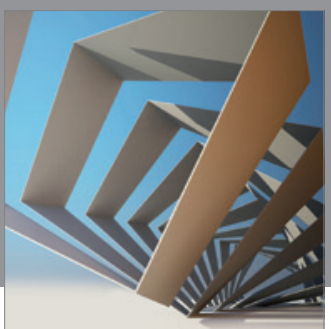

Rotating

Machinery
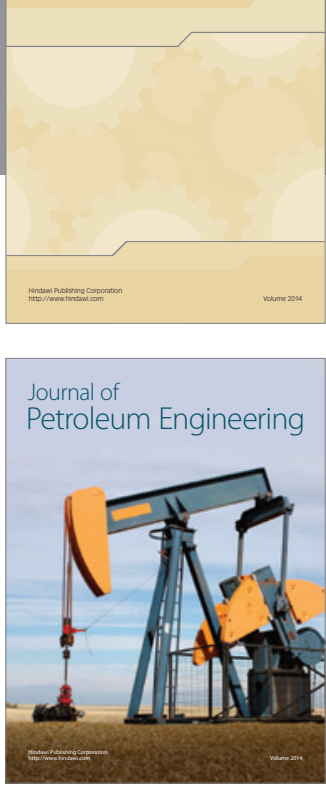

Journal of

Solar Energy
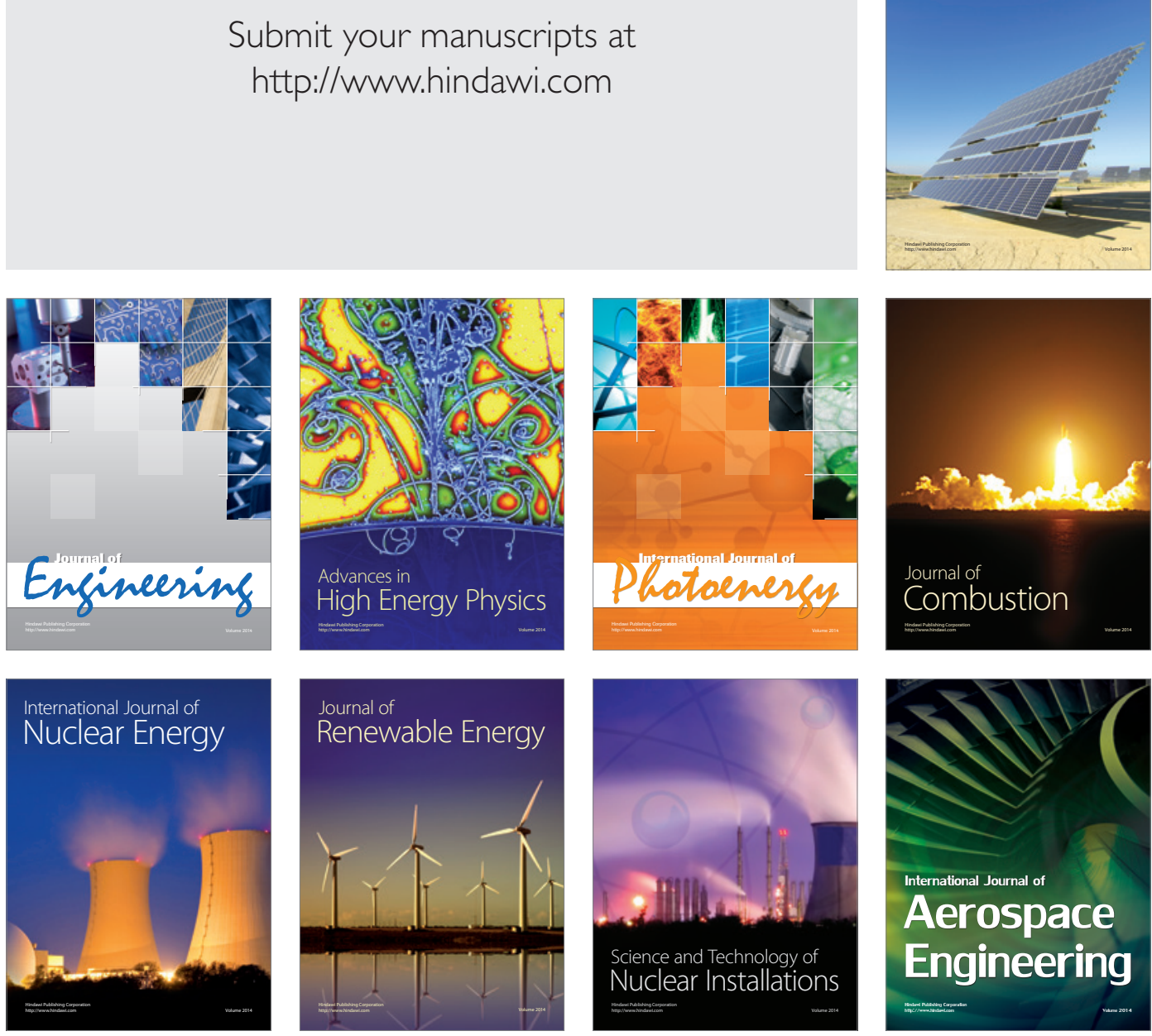